\title{
Obtención de $\beta$-glucanos de esporomas silvestres y micelio in vitro de Lycoperdon perlatum
}

\section{Obtaining of $\beta$-glucans from wild sporomes and in vitro mycelium of Lycoperdon perlatum}

\author{
César Díaz-Talamantes 1, Cristina Burrola-Aguilar 1, María Elena Estrada-Zúñiga 1, Carmen Zepeda-Gómez ${ }^{2}$ \\ ${ }^{1}$ Centro de Investigación en Recursos Bióticos, Universidad Autónoma del Estado de México. Carretera Toluca-Ixtlahuaca km 14.5, \\ San Cayetano, C.P. 50295, Toluca, Estado de México, México. \\ ${ }^{2}$ Facultad de Ciencias, Universidad Autónoma del Estado de México. Carretera Toluca-Ixtlahuaca km 15.5, El Cerrillo Piedras Blancas, \\ C.P. 50200, Toluca, Estado de México, México.
}

\section{RESUMEN}

Antecedentes: Lycoperdon perlatum es un hongo silvestre comestible valorado tradicionalmente como alimento nutritivo, con propiedades terapéuticas y medicinales, además de presentar potencial biotecnológico.

Objetivo: El objetivo fue evaluar la producción de $\beta$-glucanos en $L$. perlatum a partir del micelio producido in vitro y de esporomas silvestres.

Métodos: Se utilizó micelio propagado en fermentación en estado líquido (LSF) y esporomas silvestres recolectados en un bosque de Pinus-Abies. La biomasa de ambos materiales fúngicos se secó y procesó para obtener los $\beta$-glucanos mediante extracciones sucesivas en solución acuosa y alcalina. Los extractos fueron purificados y caracterizados por espectroscopía infrarroja por transformada de Fourier (FTIR).

Resultados y conclusiones: Se encontró que los esporomas presentaron la mayor concentración de $\beta$-glucanos con 13.80 $\mathrm{g}$ de $\beta$-glucanos totales por $100 \mathrm{~g}$ de biomasa seca, de los cuales, $2.36 \mathrm{~g}$ de $\beta$-glucanos por $100 \mathrm{~g}$ de biomasa seca corresponden a la fracción acuosa y $11.58 \mathrm{~g}$ a la fracción alcalina. El micelio presentó $11.50 \mathrm{~g}$ de $\beta$-glucanos por 100 $\mathrm{g}$ de biomasa seca, de los cuales $1.40 \mathrm{~g}$ corresponden a fracción acuosa y $10.11 \mathrm{~g}$ corresponden a fracción alcalina. El espectro FTIR de los precipitados muestra las bandas características de un $\beta$-glucano.

Palabras clave: compuesto bioactivo, cultivo in vitro, hongo comestible, medio de cultivo no convencional, producción de biomasa

\section{ABSTRACT}

Background: Lycoperdon perlatum is a wild edible mushroom traditionally valued as a nutritious food with therapeutic and medicinal properties with biotechnological potential.

Objectives: The aim of this study was to evaluate the production of $\beta$-glucans from mycelium grownin vitro and from sporomes of wild Lycoperdom perlatum.

Methods: Mycelium was cultured in vitro by liquid state fermentation (LSF), while wild sporomes were collected from a forest of Pinus and Abies. The biomass of both fungal materials was dried and processed to extract the $\beta$-glucans by successive extraction in aqueous and alkaline solution. The extracts were subsequently purified and characterized by Fourier transform infrared spectroscopy (FTIR).

Results and conclusions: The sporomes presented a higher concentration of $\beta$-glucans, with $13.80 \mathrm{~g}$ of total $\beta$-glucans per $100 \mathrm{~g}$ of dry biomass, of which, $2.36 \mathrm{~g}$ correspond to an aqueous fraction and $11.58 \mathrm{~g}$ correspond to an alkaline fraction. The mycelium presented $11.50 \mathrm{~g}$ of $\beta$-glucans per $100 \mathrm{~g}$ of dry biomass, of which, $1.40 \mathrm{~g}$ correspond to an aqueous fraction, and $10.11 \mathrm{~g}$ correspond to an alkaline fraction. The FTIR spectrum of the four precipitates show the characteristic bands of a $\beta$-glucan.

Keywords: bioactive compound, biomass production, edible mushroom, in vitro culture, unconventional culture medium

\section{ARTICLE HISTORY}

Received: 31 July 2021 / Accepted: 08 October 2021

Published on line: 25 November 2021

\section{CORRESPONDING AUTHOR}

Cristina Burrola-Aguilar, cba@uaemex.mx

ORCID 0000-0003-3499-8668 


\section{INTRODUCCIÓN}

Los hongos comestibles se consideran alimentos funcionales ya que en su estructura contienen sustancias bioactivas como los $\beta$-glucanos (Wasser 2002), los cuales son considerados responsables de actividades biológicas benéficas para la salud humana como inmunomoduladores, anticancerígenos, antitumorales, entre otros (Reis et al. 2017). Debido a estos compuestos bioactivos, los hongos comestibles y medicinales se consideran una alternativa para el tratamiento de diversas enfermedades (Sari et al. 2017).

Los $\beta$-glucanos se encuentran en la pared celular de los hongos (Basidiomycetes) (Khan et al. 2018), ya sea de los esporomas o del micelio (Arango y Nieto 2013). Los $\beta$-glucanos son polímeros compuestos de unidades de glucosa unidas por enlaces glicosídicos de tipo $\beta(1 \rightarrow 3)$ y ramificaciones laterales unidas por enlaces $\beta(1 \rightarrow 6)$ (Pizarro et al. 2014). A pesar de presentar una composición simple de monosacáridos, los $\beta$-glucanos muestran una gran variabilidad estructural (Synytsya y Novak 2014). Esta variabilidad estructural les confiere diferentes propiedades fisicoquímicas como: masa molecular, longitud de sus cadenas (Wasser 2002), solubilidad (Xiao et al. 2004), frecuencia de ramificación (Miyazaki et al. 1979), estructuras y conformación en solución (Khan et al. 2018), que son los responsables de la actividad biológica y, por tanto, de su efecto sobre la salud humana.

El cultivo in vitro para producir el micelio, es una alternativa versátil y confiable para la obtención de biomasa mediante la recolección de esporomas de su entorno natural, ya que estas técnicas requieren menos espacio y tiempo de crecimiento, se reducen las posibilidades de contaminación (Bae et al. 2000; Abdullah et al. 2013) y se facilita la manipulación de las variables que afectan la producción, composición, calidad y eficiencia de la biomasa (Arango y Nieto 2013; Chegwin-Angarita y Nieto-Ramírez 2014).

Lycoperdon perlatum (Pers) 1796 (Lycoperdaceae) es un hongo comestible, valorado culturalmente como alimento de importancia nutricional en México (Burrola-Aguilar et al. 2012). Asimismo, en la medicina tradicional se le atribuyen propiedades curativas (Guzmán 1994) y se utiliza para tratar heridas, quemaduras, verrugas, picaduras de avispas o abejas (Guzmán 2008). Estudios científicos han demostrado que la actividad enzimática esterolítica de los esporomas silvestres de
L. perlatum tiene aplicaciones en la síntesis de productos químicos para la industria farmacéutica (Colak et al. 2009), así como la actividad antioxidante y antimicrobiana de extractos de metanol (Ramesh y Pattar 2010) y actividad antiproliferativa en una línea celular de cáncer de mama humano MCF-7 de extractos acuosos, etanólicos y hexánicos (Novaković et al. 2015). Sin embargo, existen pocos estudios relacionados con el cultivo in vitro y la bioactividad de los $\beta$-glucanos de L. perlatum. Debido al potencial biotecnológico que presenta L. perlatum y a los escasos estudios sobre la bioactividad de los compuestos presentes en esta especie, este trabajo tiene el objetivo de evaluar la producción de fracciones acuosas y alcalinas de $\beta$-glucanos a partir de micelio cultivado in vitro y en esporomas silvestres de L. perlatum.

\section{MATERIALES Y MÉTODOS}

\section{Obtención de biomasa}

Material biológico. El micelio de L. perlatum se obtuvo a partir de la cepa IE987 depositada en el Instituto de Ecología A.C. Además, se utilizaron esporomas silvestres de $L$. perlatum, recolectados de bosques de Abies-Pinus a 3100-3400 msnm, en junio-agosto de 2019 en un bosque de alta montaña del Área de Protección de Flora y Fauna Nevado de Toluca (APFFNT), México.

Cultivo in vitro. Se inocularon discos impregnados con micelio de la cepa IE987 de L. perlatum (Díaz-Talamantes et al. 2017) en matraces de $500 \mathrm{~mL}$ con $300 \mathrm{~mL}$ de caldo de cultivo de maíz (formulado con $15 \mathrm{~g} \mathrm{~L}^{-1}$ de harina de maíz, $2 \mathrm{~g} \mathrm{~L}^{-1}$ de extracto de levadura y $1 \mathrm{~g} \mathrm{~L}^{-1}$ de peptona gelatina). Posteriormente, los matraces se incubaron durante 28 días bajo un fotoperiodo de 12 horas de luz y 12 horas de oscuridad, $\mathrm{pH} 6.4$, agitación orbital a $150 \mathrm{rpm}$ y una temperatura de $20^{\circ} \mathrm{C}$. Una vez finalizado el periodo de incubación, se filtró el micelio del caldo de cultivo, se lavó con agua destilada y se secó en un horno a $30^{\circ} \mathrm{C}$ durante 48 horas. Se calculó la tasa de producción de biomasa (TPB, ecuación 1) y el contenido de agua (\% de agua, ecuación 2). Finalmente, se utilizó la biomasa seca (BS) para la extracción de $\beta$-glucanos.

$\mathrm{TPB}=\begin{gathered}\text { Peso seco de la biomasa final }(\mathrm{g}) \text {-peso seco de la biomasa inicial }(\mathrm{g}) \\ \text { volumen del medio }(\mathrm{L}) * \text { tiempo de incubación (dias) }\end{gathered}$

EC. 1 
$\%$ de agua $=\frac{\text { Peso seco de la hiomasa inicial }(\mathrm{g}) \text {-peso seco de la hiomasa final }(\mathrm{g})}{\text { peso seco de la biomasa inicial }(\mathrm{g})} 100$

EC. 2

Esporomas. Los esporomas frescos (38.72 g) se caracterizaron e identificaron taxonómicamente de acuerdo a Franco-Maass et al. (2012). Posteriormente, se secaron en una estufa a $30^{\circ} \mathrm{C}$ durante 48 horas, se calculó el contenido de agua (ecuación 2) y se molieron para obtener un polvo, que se utilizó para la extracción de $\beta$-glucanos.

\section{Extracción y purificación de $\beta$-glucanos}

Macerado de biomasa. La biomasa seca del micelio (1.70 g) y de los esporomas (5.82 g) se colocaron independientemente en un recipiente con 10 volúmenes de etanol al 70 \% durante 24 horas; este procedimiento se realizó dos veces (Carbonero et al. 2006). Posteriormente, se eliminó el etanol mediante un filtro de papel de poro grueso y se recuperó la biomasa.

Extracción acuosa. La biomasa recuperada (micelio y esporomas) de la maceración se colocó en 10 volúmenes de agua destilada y la extracción se realizó en autoclave a $121^{\circ} \mathrm{C}$ durante $60 \mathrm{~min}$ (Klaus et al. 2011). El extracto resultante se colocó en una parrilla a $100{ }^{\circ} \mathrm{C}$ durante una hora para disminuir el volumen de agua (Smiderle et al. 2013). Posteriormente, la biomasa se filtró sobre un papel de filtro con un poro de $125 \mu \mathrm{m}$, obteniendo una fracción acuosa en el filtrado y la biomasa sobrante en el residuo.

Extracción alcalina. La biomasa recuperada (micelio y esporomas) de la extracción acuosa se colocó en un recipiente con 10 volúmenes de una solución alcalina de $\mathrm{NaOH}$ al $2 \%(\mathrm{p} / \mathrm{v})$ con $0.1 \%$ de $\mathrm{NaBH}_{4}$; la solución con la biomasa se calentó a $80{ }^{\circ} \mathrm{C}$ durante 4 horas. Posteriormente se agregó ácido acético al 99.9 \% gota a gota hasta obtener un pH neutro (Klaus et al. 2011). La biomasa se filtró sobre un papel filtro de poros de $125 \mu \mathrm{m}$. Con esto se obtuvo una fracción alcalina en el filtrado (Mizuno et al. 1992) y se descartó el residuo de biomasa.

Precipitación de fracciones con etanol y congelación-descongelación. La fracción acuosa y la fracción alcalina se colocaron individualmente en un recipiente con 3 volúmenes de etanol frío (Smiderle et al. 2013) para deshidratar los polisacáridos y generar un precipitado, el cual fue recuperado (Mizuno et al. 1992;
Carbonero et al. 2006). El precipitado obtenido de cada fracción contenía una cantidad significativa de residuos del proceso de extracción (agua y $\mathrm{NaOH}$ ), por lo que se congeló y descongeló lentamente a temperatura ambiente; este proceso se repitió varias veces hasta que no hubo precipitado del sobrenadante. El precipitado se recuperó y se centrifugó a 8000 rpm durante 15 minutos a una temperatura de $15^{\circ} \mathrm{C}$ (Smiderle et al. 2013). El precipitado de la centrifugación se filtró sobre una membrana de acetato de celulosa con un poro de $0.2 \mu \mathrm{m}$. Finalmente, se obtuvieron cuatro precipitados: fracción acuosa de micelio (FAqM), fracción alcalina de micelio (FAkM), fracción acuosa de esporomas (FAqBF) y fracción alcalina de esporomas (FAkBF). Estos precipitados se utilizaron para su identificación.

Identificación de fracciones. Una muestra de cada fracción $(0.1 \mathrm{~g})$ se secó en estufa a $30{ }^{\circ} \mathrm{C}$ durante 48 horas hasta obtener cristales, los cuales se caracterizaron por FTIR bajo una absorbancia en el rango de 400- $4000 \mathrm{~cm}^{-1}$ mediante la técnica de disco KBr (Mizuno et al. 1992; Klaus et al. 2011) para identificar la presencia de enlaces característicos de los $\beta$-glucanos correspondientes a OH en $3200 \mathrm{~cm}^{-1}$, CH en $2922 \mathrm{~cm}^{-1}$, $\mathrm{CO}$ en $1644 \mathrm{~cm}^{-1}$ (Alzorqi et al. 2017), además de las regiones asociadas a azúcares en un intervalo de 1200 $\mathrm{cm}^{-1}$ a $950 \mathrm{~cm}^{-1}$ y la región anomérica que va de 950 $\mathrm{cm}^{-1}$ a $750 \mathrm{~cm}^{-1}$ (Synytsya y Novak 2014).

\section{RESULTADOS}

Obtención de biomasa

El cultivo de micelio in vitro presentó un peso fresco de $40.87 \mathrm{~g}$ con $96.5 \%$ de contenido de agua y BPR de $0.04 \mathrm{~g} \mathrm{~L}^{-1}$ día $^{-1}$. Los esporomas de $L$. perlatum son pseudoestipitados redondos, de $3.5-7.5 \mathrm{~cm}$ de largo, de color blanco y crema, su hábitat suele ser terrícola o humícola, crece en bosques de Abies-Pinus a altitudes de 3100-3400 metros. Los esporomas presentaron un peso fresco de $38.72 \mathrm{~g}$ con $84.89 \%$ de contenido de agua. Microscópicamente presentan basidiosporas de (3.0-) $3.77(-4.0) \mu \mathrm{m}$, redondas y ligeramente espinuladas, correspondientes a las características de la especie (Franco-Maass et al. 2012).

\section{Extracción y purificación de $\boldsymbol{\beta}$-glucanos}

El contenido total de $\beta$-glucanos presentes en el micelio fue de $11.50 \mathrm{~g}$ de $\beta$-glucanos por $100 \mathrm{~g}$ de biomasa 
seca, de los cuales $1.40 \mathrm{~g}$ de $\beta$-glucanos por $100 \mathrm{~g}$ de biomasa seca corresponden a FrAgM y $10.11 \mathrm{~g}$ de $\beta$-glucanos por $100 \mathrm{~g}$ de biomasa seca corresponden a FrAkM. En cuanto a los esporomas, se obtuvieron 13.80 $\mathrm{g}$ de $\beta$-glucanos totales por $100 \mathrm{~g}$ de biomasa seca, de los cuales, $2.36 \mathrm{~g}$ de $\beta$-glucanos por $100 \mathrm{~g}$ de biomasa seca corresponden a FrAqBF y $11.58 \mathrm{~g}$ de $\beta$-glucanos por $100 \mathrm{~g}$ de biomasa seca corresponde a FrAkBF.

\section{Identificación de fracciones}

Los espectros FTIR obtenidos de las fracciones correspondientes a FrAqM, FrAkM (Figura 1), FrAqBF y FrAkBF (Figura 2) concuerdan con el espectro de un $\beta$-glucano (Movasaghi et al. 2008), debido a que se observan las bandas características: una banda a 3200 $\mathrm{cm}^{-1}$ correspondiente a la región de las vibraciones de los enlaces $\mathrm{OH}$, una banda correspondiente a 2922 $\mathrm{cm}^{-1}$ que se atribuye a la presencia de enlaces $\mathrm{CH}$ saturados (Figuras 1 y 2) (Šandula et al. 1999). El espectro de FrAqBF, FrAkBF (Figura 2) y FrAkM (Figura 1) mostró una señal de absorción a $1644 \mathrm{~cm}^{-1}$, que está relacionada con las vibraciones de estiramiento del enlace CO (carbonilo) de un complejo polisacárido-proteína (Alzorqi et al. 2017), debido a esto, los $\beta$-glucanos de estas fracciones podrían acoplarse a una proteína. De esta manera, las cuatro fracciones (Figuras 1 y 2) presentan las dos regiones fundamentales de los $\beta$-glucanos, la "región de azúcar" que va desde $1.200 \mathrm{~cm}^{-1}$ a $950 \mathrm{~cm}^{-1}$ y la "región anomérica" que va desde 950 $\mathrm{cm}^{-1}$ a los $750 \mathrm{~cm}^{-1}$ (Synytsya y Novak 2014). En estas regiones, se observan las bandas características de los enlaces carbono-glucósido del $\beta$-glucano correspondientes a 1160, 1080, 1040, 970 y $890 \mathrm{~cm}^{-1}$ (Alzorqi et al. 2017). Por otro lado, en los espectros de las cuatro fracciones se observa una señal que va de 1160 a $1147 \mathrm{~cm}^{-1}$. Münzberg et al. (1995) menciona que esta señal representa el estiramiento del enlace glucosídico COC, donde la señal en $1040 \mathrm{~cm}^{-1}$ corresponde al estiramiento de $\mathrm{CO}$. También menciona que la disminución de la señal de absorción a $1080 \mathrm{~cm}^{-1}$ y la desaparición de la señal a $890 \mathrm{~cm}^{-1}$ en las fracciones alcalinas FrAkM (Figura 1) y FrAkBF (Figura 2) debe ser una degradación del polisacárido en la base cadena.

La producción de $\beta$-glucanos en las fracciones obtenidas es similar entre el micelio y los esporomas. Sin embargo, se observa una mayor producción de $\beta$-glucanos en el FrAkM y FrAkBF correspondientes a la fracción alcalina.

\section{DISCUSIÓN}

Actualmente existe una demanda creciente de hongos comestibles silvestres que brindan beneficios a la salud humana (Wasser 2002) como es el caso de L. perlatum. Además, es relevante destacar que existen pocos estudios relacionados con el cultivo in vitro de esta especie y en general de la familia Lycoperdaceae. Por tanto, es de gran importancia realizar más estudios biotecnoló-

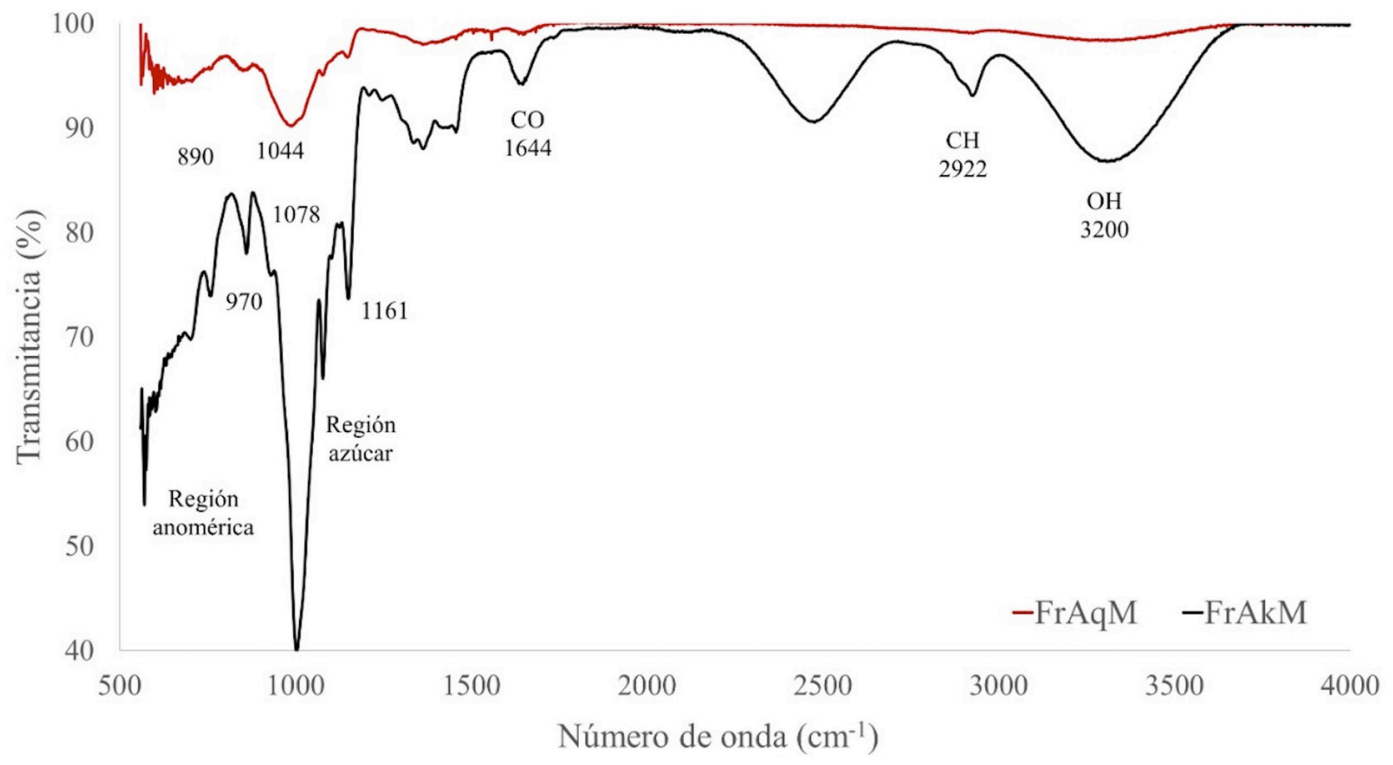

Figura 1.- Espectro FTIR de la fracción acuosa de micelio (FrAqM) y fracción alcalina del micelio (FrAkM) de L. perlatum. 


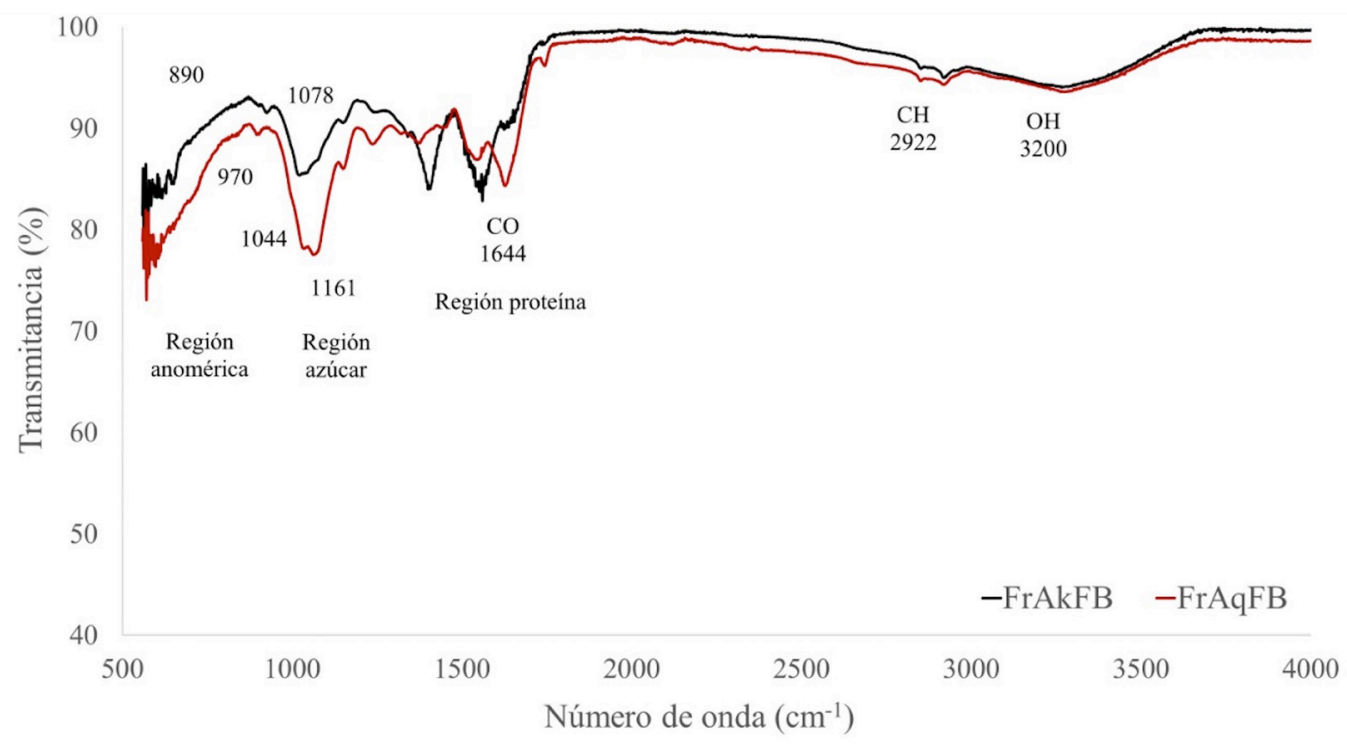

Figura 2.- Espectro FTIR de la fracción acuosa de esporomas (FrAqFB) y fracción alcalina de esporomas (FrAkFB) de L. perlatum.

gicos para la selección de cepas y optimización de las condiciones de cultivo in vitro (Song et al. 1998). La producción in vitro de micelio de L. perlatum se vio afectada por diferentes factores como: el medio de cultivo utilizado a base de harina de maíz. Según Chegwin-Angarita y Nieto-Ramírez (2014) las fuentes de carbono no convencionales como las harinas de cereales tienden a incrementar la producción de biomasa. Wang et al. (2005) menciona que la relación carbono-nitrógeno para mejorar la producción de biomasa de hongos oscila entre 40:1; similar al que presenta un medio a base de harina de maíz (Chegwin-Angarita y Nieto-Ramírez 2014). Por ello, la relación carbono-nitrógeno proporcionada por el medio de cultivo utilizado podría ayudar a maximizar la producción de biomasa. Otros factores de importancia para el cultivo in vitro de $L$. perlatum son la temperatura entre 18 y 25 ${ }^{\circ} \mathrm{C}$, y el pH mayor a 5.8 (Díaz-Talamantes et al. 2017). En este estudio, el crecimiento micelial mantuvo las condiciones óptimas para la producción de biomasa, la temperatura fue de $20^{\circ} \mathrm{C}$ y el $\mathrm{pH}$ disminuyó de 6.4 a 6.1 .

El contenido de agua es una variable primordial en la producción de metabolitos estructurales, ya que está directamente relacionado con el contenido de biomasa seca (Arango y Nieto 2013). Según Rathore et al. (2017) aproximadamente la mitad de la biomasa en peso seco de la pared celular de los basidiomicetos está constituida por metabolitos estructurales entre ellos $\beta$-glucanos. En este estudio, el micelio presentó $96.5 \%$ de contenido de agua y los esporomas un 84.89 $\%$, por lo que, los esporomas presentaron una mayor concentración de $\beta$-glucanos en la biomasa seca.

La producción de $\beta$-glucanos totales presentes en las fracciones de micelio (11.50 g de $\beta$-glucanos por $100 \mathrm{~g}$ de BS) y esporomas (13.80 g de $\beta$-glucanos por $100 \mathrm{~g}$ de BS) se encuentran en el rango reportado, como lo sugiere Sari et al. (2017), donde el contenido de $\beta$-glucanos en esporomas silvestres de $L$. perlatum fue de 15.48-19.749 $\mathrm{g}$ de $\beta$-glucanos por $100 \mathrm{~g}$ de BS.

Además, la concentración de $\beta$-glucanos presentes en las fracciones alcalinas FrAkM y FrAkBF fue mayor que la fracción acuosa FrAqM y FrAqBF. Según Tseng et al. (2008) esto se debe a que en el proceso de extracción las paredes celulares se degradan y los compuestos insolubles en agua se transforman en componentes solubles. Sin embargo, es importante mencionar que la fracción acuosa de $\beta$-glucanos normalmente tiene mayor bioactividad que las insolubles (Xiao et al. 2004).

Existen otros factores que pueden afectar la producción de biomasa y $\beta$-glucanos presentes en esporomas y micelio in vitro. De acuerdo a Papaspyridi et al. (2010) el micelio representa la fase vegetativa del hongo, mientras que los esporomas la fase reproductiva, y la función estructural de los $\beta$-glucanos en la pared celular varía en cada fase. De la misma manera, la producción de biomasa y la bioactividad de los $\beta$-glucanos también se ven afectada por la fuente de nutrien- 
tes. Según Ooi y Liu (2000) el sustrato natural donde se desarrollan los esporomas silvestres puede contener compuestos polifenólicos que inducen la síntesis de $\beta$-1,3-glucano sintasa, aumentando la producción de $\beta$-glucanos.

Reis et al. (2017) mencionan que los esporomas normalmente presentan mayor bioactividad que los sistemas in vitro, debido a que la composición química varía en relación a los nutrientes del sustrato.

Lycoperdon perlatum es un hongo saprobio (Rinaldi et al. 2008) tradicionalmente valorado como hongo medicinal (Guzmán 2008), se ha demostrado que es una especie viable para el cultivo in vitro (Díaz-Talamantes et al. 2017). Es importante desarrollar más estudios para conocer las variables que permitan maximizar la producción de biomasa y $\beta$-glucanos. Como por ejemplo el medio de cultivo, fuente de carbono, $\mathrm{pH}$, temperatura y disponibilidad de oxígeno; además de la bioactividad de los $\beta$-glucanos y posibles aplicaciones medicinales, farmacéuticas y nutricionales; y conservación y manejo del recurso en su hábitat natural. Asimismo, es importante resaltar que existe una gran variabilidad en la estructura de $\beta$-glucanos presentes en hongos (Synytsya y Novak 2014), debido a esto, los $\beta$-glucanos de algunas especies presentan mayor bioactividad, especialmente aquellas especies con propiedades medicinales como L. perlatum.

\section{CONCLUSIONES}

El cultivo in vitro de Lycoperdon perlatum es una alternativa viable para la producción de metabolitos de interés biotecnológico como los $\beta$-glucanos, debido a que la producción de biomasa en fermentación en estado líquido presenta una concentración de $\beta$-glucanos similar a la de los esporomas. Además, en el cultivo in vitro es posible controlar factores y variables que afectan la producción y calidad de biomasa y de $\beta$-glucanos, así como contar con el material biológico sin depender de su recolección, ayudando al manejo y conservación de este recurso en los bosques.

Por otro lado, la presencia de $\beta$-glucanos obtenidos tanto en el micelio in vitro como en los esporomas, son mayores en la fracción alcalina, esto debido a que el proceso de extracción se realiza con una solución salina que es más agresiva con la pared celular facilitando así su extracción.
Estos compuestos bioactivos son de gran importancia para futuras investigaciones médicas como inmunomoduladores, tratamiento contra diferentes tipos de cáncer y tumores, además de su aplicación como nutracéuticos en la industria alimentaria.

\section{AGRADECIMIENTOS}

Los autores agradecen a la Secretaría de Educación Pública y a la Universidad Autónoma del Estado de México por el financiamiento de este proyecto, a través del Apoyo para Fortalecimiento de Cuerpos Académicos en Formación del Programa para el Desarrollo Profesional Docente de la Secretaría de Educación Pública (PRODEP-SEP) 2018 (Proyecto No. 4615/2018 CA: "Avances etnofarmacológicos, nutricionales y nutricéuticos de los recursos vegetales y fúngicos prioritarios para las comunidades del Santuario de Agua Presa Corral de Piedra) así como al Consejo Nacional de Ciencia y Tecnología (CONACyT) por la beca otorgada al primer autor para sus estudios en el Posgrado de Ciencias Agropecuarias y Recursos Naturales de la Universidad Autónoma del Estado de México.

\section{LITERATURA CITADA}

Abdullah N, Ismail R, Johari NMK, Annuar M. 2013. Production of liquid spawn of an edible grey oyster mushroom, Pleurotus pulmonarius (Fr.) Quél by submerged fermentation and sporophore yield on rubber wood sawdust. Scientia Horticulturae 161, 65-69. https://doi.org/10.1016/j.scienta.2013.06.026

Alzorqi I, Sudheer S, Lu TJ, Manickam S. 2017. Ultrasonically extracted $\beta$-d-glucan from artificially cultivated mushroom, characteristic properties and antioxidant activity. Ultrasonics Sonochemistry 35, 531-540. https://doi.org/10.1016/j.ultsonch.2016.04.017

Arango CS, Nieto IJ. 2013. Cultivo biotecnológico de macrohongos comestibles: una alternativa en la obtención de nutracéuticos. Revista Iberoamericana de Micología 30, 1-8. https://doi.org/10.1016/j.riam.2012.03.011

Bae JT, Sinha J, Park JP, Song CH, Yun JW. 2000. Optimization of submerged culture conditions for exo-biopolymer production by Paecilomyces japonica. Journal of Microbiology and Biotechnology 10, 482-487. https://doi.org/10.1007/s11274-004-5841-x

Burrola-Aguilar C, Montiel O, Garibay-Orijel R, Zizumbo-Villarreal L. 2012. Conocimiento tradicional y aprovechamiento de los hongos comestibles silvestres en la región de Amanalco, Estado de México. Revista Mexicana de Micología 35, 1-16.

Carbonero ER, Gracher AHP, Smiderle FR, Rosado FR, Sassaki GL, Gorin PA, lacomini M. 2006. A $\beta$-glucan from the fruit bodies of edible mushrooms Pleurotus eryngii and Pleurotus ostreatoroseus. Carbohydrate Polymers 66, 252-257. https://doi.org/10.1016/j.carbpol.2006.03.009

Colak A, Camedan Y, Faiz O, Sesli E, Kolcuoğlu Y. 2009. An esterolytic activity from a wild edible mushroom, Lycoperdon perlatum. Journal of Food Biochemistry 33, 482-499. https://doi. org/10.1111/j.1745-4514.2009.00232.x

Chegwin-Angarita C, Nieto-Ramírez IJ. 2014. Effect of non-conventional carbon sources on the production of triterpenoids in submerged cultures of Pleurotus macrofungi. Journal of the Chilean 
Chemical Society 59, 2287-2293. http://dx.doi.org/10.4067/ S0717-97072014000100010

Díaz-Talamantes C, Burrola-Aguilar C, Aguilar-Miguel X, Mata G. 2017. Crecimiento miceliar in vitro de hongos comestibles silvestres de alta montaña en el centro de México. Revista Chapingo Serie Ciencias Forestales y del Ambiente 23, 369-383. https:// doi.org/10.5154/r.rchscfa.2016.12.067

Franco Maass S, Burrola Aguilar C, Arana Gabriel Y. 2012. Hongos silvestres comestibles: un recurso forestal no maderable del $\mathrm{Ne}$ vado de Toluca. Ediciones EON, México, D.F.

Guzmán G. 1994. Los hongos en la medicina tradicional de Mesoamérica y de México. Revista Iberoamericana de Micología 11, 81-85.

Guzmán G. 2008. Diversity and use of traditional Mexican medicinal fungi. A review. International Journal of Medicinal Mushrooms 10, 209-217 https://doi.org/10.1615/IntJMedMushr.v10.i3.20

Khan AA, Gani A, Khanday FA, Masoodi F. 2018. Biological and pharmaceutical activities of mushroom $\beta$-glucan discussed as a potential functional food ingredient. Bioactive Carbohydrates and Dietary Fibre 16, 1-13. https://doi.org/10.1016/j.bcdf.2017.12.002

Klaus A, Kozarski M, Niksic M, Jakovljevic D, Todorovic N, Van Griensven LJ. 2011. Antioxidative activities and chemical characterization of polysaccharides extracted from the basidiomycete Schizophyllum commune. LWT-Food Science and Technology 44, 2005-2011. https://doi.org/10.1016/j.Iwt.2011.05.010

Miyazaki T, Oikawa N, Yadomae T, Yamada H, Yamada Y, Hsu HY, Ito H. 1979. Relationship between the chemical structure and anti-tumour activity of glucans prepared from Grifora umbellata. Carbohydrate Research 69, 165-170. https://doi.org/10.1016/ s0008-6215(00)85761-4

Mizuno T, Ando M, Sugie R, Ito $H$, Shimura K, Sumiya T, Matsuura A. 1992. Antitumor activity of some polysaccharides isolated from an edible mushroom, Ningyotake, the fruiting body and the cultured mycelium of Polyporous confluens. Bioscience, Biotechnology and Biochemistry 56, 34-41. https://doi.org/10.1271/ bbb.56.34

Movasaghi Z, Rehman S, Rehman DI. 2008. Fourier transform infrared (FTIR) spectroscopy of biological tissues. Applied Spectroscopy Reviews 43, 134-179. https://doi. org/10.1080/05704920701829043

Münzberg J, Rau U, Wagner F. 1995. Investigations on the regioselective hydrolysis of a branched $\beta$-1, 3-glucan. Carbohydrate Polymers 27, 271-276. https://doi.org/10.1016/01448617(95)00069-0

Novaković AR, Karaman MA, Matavulj MN, Pejin BM, Belović MM, Radusin TI, Ilić NM. 2015. An insight into in vitro bioactivity of wild-growing puffball species Lycoperdon perlatum (Pers) 1796. Food and Feed Research 42, 51-58. https://doi.org/10.5937/ FFR1501051N

Ooi VE, Liu F. 2000. Immunomodulation and anti-cancer activity of polysaccharide-protein complexes. Current Medicinal Chemistry 7, 715-729. https://doi.org/10.2174/0929867003374705

Papaspyridi LM, Katapodis P, Gonou-Zagou Z, Kapsanaki-Gotsi E, Christakopoulos P. 2010. Optimization of biomass production with enhanced glucan and dietary fibres content by Pleurotus ostreatus ATHUM 4438 under submerged culture. Biochemical
Engineering Journal 50, 131-138. https://doi.org/10.1016/j. bej.2010.04.008

Pizarro S, Ronco AM, Gotteland M. 2014. B-glucanos: ¿Qué tipos existen y cuáles son sus beneficios en la salud? Revista Chilena de Nutrición 41, 439-446. http://dx.doi.org/10.4067/S071775182014000400014

Ramesh C, Pattar M.G. 2010. Antimicrobial properties, antioxidant activity and bioactive compounds from six wild edible mushrooms of western ghats of Karnataka, India. Pharmacognosy Research 2, 107. https://doi.org/10.4103/0974-8490.62953

Rathore H, Prasad S, Sharma S. 2017. Mushroom nutraceuticals for improved nutrition and better human health: A review. PharmaNutrition 5, 35-46. https://doi.org/10.1016/j.phanu.2017.02.001

Reis FS, Martins A, Vasconcelos MH, Morales P, Ferreira IC. 2017. Functional foods based on extracts or compounds derived from mushrooms. Trends in Food Science \& Technology 66, 48-62. https://doi.org/10.1016/j.tifs.2017.05.010

Rinaldi A, Comandini O, Kuyper TW. 2008. Ectomycorrhizal fungal diversity: separating the wheat from the chaff. Fungal Diversity $33,1-45$.

Šandula J, Kogan G, Kačuráková M, Machová E. 1999. Microbial $(1 \rightarrow 3)-\beta-D-g l u c a n s$, their preparation, physico-chemical characterization and immunomodulatory activity. Carbohydrate Polymers 38, 247-253. https://doi.org/10.1016/S0144-8617(98)00099-X

Sari M, Prange A, Lelley JI, Hambitzer R. 2017. Screening of Beta-glucan contents in commercially cultivated and wild growing mushrooms. Food Chemistry 216, 45-51. https://doi.org/10.1016/j. foodchem.2016.08.010

Smiderle FR, Alquini G, Tadra-Sfeir MZ, lacomini M, Wichers HJ, Van Griensven LJ. 2013. Agaricus bisporus and Agaricus brasiliensis $(1 \rightarrow 6)-\beta$-d-glucans show immunostimulatory activity on human THP-1 derived macrophages. Carbohydrate Polymers 94, 91-99. https://doi.org/10.1016/j.carbpol.2012.12.073

Song C, Jeon Y, Yang B, Ra K, Kim H. 1998. Anti-complementary activity of endopolymers produced from submerged mycelial culture of higher fungi with particular reference to Lentinus edodes. Biotechnology Letters 20, 741-744. https://doi.org/10.1023/A:1005334719522

Synytsya A, Novak M. 2014. Structural analysis of glucans. Annals of Translational Medicine 2(2), 17. https://doi.org/10.3978/j. issn.2305-5839.2014.02.07

Tseng YH, Yang JH, Mau JL. 2008. Antioxidant properties of polysaccharides from Ganoderma tsugae. Food Chemistry 107, 732738. https://doi.org/10.1016/j.foodchem.2007.08.073

Wang JC, Hu SH, Liang ZC, Yeh CJ. 2005. Optimization for the production of water-soluble polysaccharide from Pleurotus citrinopileatus in submerged culture and its antitumor effect. Applied Microbiology and Biotechnology 67, 759-766. https://doi. org/10.1007/s00253-004-1833-x

Wasser S. 2002. Medicinal mushrooms as a source of antitumor and immunomodulating polysaccharides. Applied Microbiology and Biotechnology 60, 258-274. https://doi.org/10.1007/s00253$\underline{002-1076-7}$

Xiao Z, Trincado CA, Murtaugh MP. 2004. $\beta$-Glucan enhancement of T cell IFNy response in swine. Veterinary Immunology and Immunopathology 102, 315-320. https://doi.org/10.1016/j.vetimm.2004.09.013 